Chronic Obstructive Pulmonary Diseases:

Journal of the COPD Foundation

Original Research

\title{
InforMing the PAthway of COPD Treatment (IMPACT Trial) Single-Inhaler Triple Therapy (Fluticasone Furoate/Umeclidinium/ Vilanterol) Versus Fluticasone Furoate/Vilanterol and Umeclidinium/Vilanterol in Patients With COPD: Analysis of the Western Europe and North America Regions
}

Arnaud Bourdin, MD, $\mathrm{PhD}^{1}$ Gerard Criner, $\mathrm{MD}^{2}$ Gilles Devouassoux, MD, $\mathrm{PhD}^{3,4}$ Mark Dransfield, $\mathrm{MD}^{5} \mathrm{David}$ M.G. Halpin, $\mathrm{MD}^{6}$ MeiLan K. Han, $\mathrm{MD}^{7}$ C. Elaine Jones, $\mathrm{PhD}^{8}$ Ravi Kalhan, $\mathrm{MD}^{9}$ Peter Lange, $\mathrm{MD}^{10,11}$ Sally Lettis, $\mathrm{PhD}^{12}$ David A. Lipson, MD ${ }^{13,14}$ David A. Lomas, $\mathrm{MD}^{15}$ José M. Echave-Sustaeta María-Tomé, MD ${ }^{16}$ Neil Martin, MD ${ }^{17,18}$ Fernando J. Martinez, MD ${ }^{19}$ Holly Quasny, PharmD ${ }^{8}$ Lynda Sail, MD ${ }^{20}$ Thomas M. Siler, $\mathrm{MD}^{21}$ Dave Singh, $\mathrm{MD}^{22}$ Byron Thomashow, $\mathrm{MD}^{23}$ Henrik Watz, $\mathrm{MD}^{24}$ Robert Wise, $\mathrm{MD}^{25}$ Nicola A. Hanania, MD, $\mathrm{MS}^{26}$

\section{Abstract}

Background: The InforMing the Pathway of COPD Treatment (IMPACT) trial demonstrated lower moderate/ severe exacerbation rates with fluticasone furoate/umeclidinium/vilanterol (FF/UMEC/VI) versus FF/VI or UMEC/VI in patients with chronic obstructive pulmonary disease (COPD) and a history of exacerbations. Since IMPACT was a global study, post-hoc analyses were conducted by geographic region to investigate potential differences in overall findings.

Methods: IMPACT was a 52-week, randomized, double-blind trial. Patients with symptomatic COPD and $\geq 1$ moderate/severe exacerbation in the prior year were randomized 2:2:1 to once-daily FF/UMEC/VI

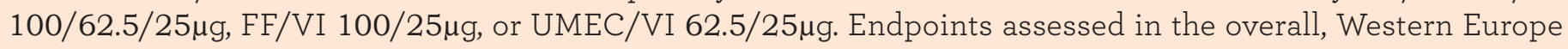
and North America populations included on-treatment moderate/severe exacerbation (rates and time-to-first), trough forced expiratory volume in 1 second and St George's Respiratory Questionnaire (SGRQ) total score. Safety was assessed.

Results: Overall, 10,355 patients were enrolled, 3164 from Western Europe, 2639 from North America. FF/ UMEC/VI significantly reduced on-treatment moderate/severe exacerbation rates versus FF/VI and UMEC/ VI in Western Europe (rate ratios 0.82 [95\% CI 0.74-0.91], $P<.001$ and 0.76 [0.67-0.87], $P<.001$ ) and in North America (0.87 [0.77-0.97], $P=.014$ and 0.69 [0.60-0.80], $P<.001$ ). FF/UMEC/VI reduced time-to-first moderate/ severe exacerbation and improved lung function versus FF/VI and UMEC/VI in both regions, and improved SGRQ total score in Western Europe, but not North America. Safety profiles were generally similar between treatment groups/regions; the inhaled corticosteroid class effect of increased pneumonia incidence was seen in North America but not Western Europe.

Conclusions: Consistent with intent-to-treat results, FF/UMEC/VI reduced moderate/severe exacerbation rate and risk and improved lung function in Western Europe and North America; however, between-regions differences were seen for SGRQ total score and pneumonia incidence.

Clinical Trial Registration: NCT02164513. 
Abbreviations: InforMing the Pathway of COPD Treatment, IMPACT; fluticasone furoate, FF; umeclidinium, UMEC; vilanterol, VI; chronic obstructive pulmonary disease, COPD; St George's Respiratory Questionnaire, SGRQ; Global initiative for chronic Obstructive Lung Disease, GOLD; COPD Assessment Test, CAT; forced expiratory volume in 1 second, FEV1; adverse events, AEs; serious AEs, SAEs; AEs of special interest, AESI; intent-to-treat, ITT; standard deviation, SD; body mass index, BMI; inhaled corticosteroids, ICSs; long-acting beta2-agonists, LABAs; long-acting muscarinic antagonists, LAMAs; Standardized Medical Dictionary for Regulatory Activities Query, SMQ; bone mineral density, BMD; diabetes mellitus, DM; lower respiratory tract infection, LRTI

Funding Support: This study was funded by GlaxoSmithKline (GSK) (study number CTT116855; NCT02164513). The funders of the study had a role in the study design, data analysis, data interpretation, and writing of the report. Editorial support (in the form of writing assistance, assembling figures, collating author comments, grammatical editing and referencing) was provided by Chrystelle Rasamison, Fishawack Indicia Ltd, United Kingdom, and was funded by GSK.

Date of Acceptance: August 21, 2020 | Published Online Date: November 5, 2020

Citation: Bourdin A, Criner G, Devouassoux G, et al. Informing the pathway of COPD treatment (IMPACT) single-inhaler triple therapy (fluticasone furoate/ umeclidinium/ vilanterol) versus fluticasone furoate/vilanterol and umeclidinium/vilanterol in patients with COPD: analysis of the Western Europe and North America regions. Chronic Obstr Pulm Dis. 2021;8(1):76-90. doi: https://doi.org/10.15326/ jcopdf. 2020.0158

1 Department of Pneumology and Addictology, University of

Montpellier, CHU Montpellier, Montpellier, France

2 Lewis Katz School of Medicine at Temple University,

Philadelphia, Pennsylvania, United States

3 Univ. Lyon, Université Claude-Bernard Lyon 1, Lyon, France

4 Hôpital de la Croix-Rousse, Service de Pneumologie, Hospices Civils de Lyon, Lyon, France

5 Division of Pulmonary, Allergy, and Critical Care Medicine, Lung Health Center, University of Alabama at Birmingham, Alabama, United States

6 College of Medicine and Health, University of Exeter Medical School, Exeter, United Kingdom

7 Pulmonary and Critical Care, University of Michigan, Ann Arbor, Michigan, United States

8 GlaxoSmithKline, Research Triangle Park, North Carolina, United States

9 Division of Pulmonary and Critical Care Medicine, Northwestern University Feinberg School of Medicine, Chicago, Illinois, United States

10 Department of Public Health, University of Copenhagen, Copenhagen, Denmark

11 Medical Department, Herlev University Hospital, Herlev, Denmark

12 GlaxoSmithKline, Stockley Park West, Uxbridge, Middlesex, United Kingdom

13 GlaxoSmithKline, Collegeville, Pennsylvania, United States

14 Perelman School of Medicine, University of Pennsylvania, Philadelphia, Pennsylvania, United States

15 UCL Respiratory, University College London, London, United Kingdom

16 Respiratory Department, Hospital Universitario Quirónsalud Madrid, Universidad Europea de Madrid, Madrid, Spain

17 GlaxoSmithKline, Brentford, Middlesex, United Kingdom

18University of Leicester, Leicester, United Kingdom

19Weill Cornell Medicine, New York, New York, United States

20 GlaxoSmithKline, Paris, France

21 Midwest Chest Consultants, PC, St. Charles, Missouri, United States

22 The University of Manchester, Manchester University National Health Service Foundation Trust, United Kingdom

23 Division of Pulmonary, Allergy, and Critical Care, Columbia University Medical Center, New York, New York, United States
24 Pulmonary Research Institute at Lungen Clinic Grosshansdorf, Airway Research Center North, German Center for Lung Research, Grosshansdorf, Germany

25 Division of Pulmonary and Critical Care Medicine, Johns Hopkins University School of Medicine, Baltimore, Maryland, United States

26 Section of Pulmonary and Critical Care Medicine, Airways Clinical Research Center, Baylor College of Medicine, Houston, Texas, United States

\section{Address correspondence to:}

Nicola A. Hanania, MD, MS

Airways Clinical Research Center

Section of Pulmonary and Critical Care Medicine

Baylor College of Medicine

1504 Taub Loop, Houston, TX

Email: hanania@bcm.edu

Telephone: +1 7138733454

\section{Keywords:}

COPD, single-inhaler triple therapy, exacerbations, Western Europe, North America

\section{This article contains an online supplement.}

\section{Introduction}

Chronic obstructive pulmonary disease (COPD) is a lung disease characterized by airflow limitation and progressive respiratory symptoms. ${ }^{1}$ Global public health trends estimate that the COPD burden will continue to rise, with COPD deaths estimated to increase to $4.4 \%$ of all deaths in Europe and $6.3 \%$ in the World Health Organization-defined region of the Americas by $2060 .^{2}$ There are differences in the COPD burden in different regions reflecting variations in etiology, ${ }^{3,4}$ disease severity, ${ }^{5}$ symptoms, ${ }^{6}$ medication use, ${ }^{7}$ and health care systems and utilization. ${ }^{7}$ These differences may help inform therapeutic strategies 
to optimize therapeutic approaches to reducing symptoms and exacerbation risk. ${ }^{1}$

In the global InforMing the PAthway of COPD Treatment (IMPACT) trial, single-inhaler triple therapy fluticasone furoate/umeclidinium/ vilanterol (FF/UMEC/VI) reduced moderate/severe exacerbation rates and improved lung function and health-related quality of life versus FF/VI or UMEC/ VI dual therapy in patients $\geq 40$ years of age with symptomatic COPD and a history of exacerbations. ${ }^{8}$ Within trial populations, regional differences such as patient characteristics, treatment patterns, access to care and cultural/socioeconomic factors may dictate treatment choices and influence disease severity and progression in particular geographical locations. For example, a meta-analysis conducted in 2015 comprising 123 studies between 1990 and 2010 found that the overall prevalence of COPD as well as the rate of increase was higher in the Americas (including both North and South America) compared with Europe. ${ }^{9}$ Furthermore, a cross-sectional study assessing the burden of COPD symptoms in the United States and Europe found variations between patients across countries who had experienced at least 1 symptom of COPD. ${ }^{10}$ In Europe, patients with more frequent symptoms were more likely to experience worsening of symptoms and unexpected hospitalization. Whereas in the United States, patients with more frequent symptoms were not only more likely to experience worsening of symptoms but also longer lasting symptoms and a longer length of exacerbations. ${ }^{10}$ A further difference was that treatment adherence was higher in the United States than Europe, however, adherence was consistent across patients in Europe when assessed by modified Global initiative for chronic Obstructive Lung Disease (GOLD) 2014 groups $^{11}$ but varied in the United States with adherence highest in the GOLD Group C and lowest in Group A. ${ }^{10}$ Therefore, it is important to evaluate how overall population results pertain to patients treated in particular regions. As IMPACT is one of the largest trials conducted in patients with COPD to date, we have the unique opportunity to analyze study outcomes in patients enrolled in Western Europe and North America, the 2 main regions from an enrollment perspective.

\section{Materials and Methods}

\section{Study Design and Patients}

IMPACT (GSK Study CTT116855; NCT02164513) was a 52-week, randomized, double-blind, parallelgroup, Phase 3 trial conducted in 37 countries. $^{8}$ The trial design has been previously described. ${ }^{8,12}$ Briefly, eligible patients with COPD were $\geq 40$ years of age, symptomatic (COPD Assessment Test [CAT] score $\geq 10$ ), and had a forced expiratory volume in 1 second $\left(\mathrm{FEV}_{1}\right)<50 \%$ predicted and $\geq 1$ moderate/ severe exacerbation in the preceding year, or $\mathrm{FEV}_{1}$ $50 \%-<80 \%$ predicted and $\geq 2$ moderate or $\geq 1$ severe exacerbation(s) in the preceding year. Patients were randomized (2:2:1) to once-daily FF/UMEC/

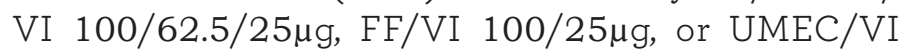
$62.5 / 25 \mu$ g administered via the ELLIPTA dry powder inhaler. Patients continued their existing COPD medications during a 2 -week run-in period and were provided with as-needed salbutamol (rescue medication). All patients provided written informed consent. The trial was conducted in accordance with Good Clinical Practice guidelines and the provisions of the Declaration of Helsinki and received approval from local institutional review boards and independent ethics committees.

\section{Endpoints, Assessments, and Data Analysis}

The primary endpoint was the annual rate of ontreatment moderate/severe exacerbations with FF/ $\mathrm{UMEC} / \mathrm{VI}$ versus FF/VI and UMEC/VI. Other efficacy endpoints included time-to-first moderate/ severe exacerbation, change from baseline in trough $\mathrm{FEV}_{1}$ and St George's Respiratory Questionnaire (SGRQ) total score at Week 52, and proportion of SGRQ responders ( $\geq 4$ unit decrease from baseline in SGRQ total score) at Week 52 . Treatment by region interaction for SGRQ total score, moderate/severe exacerbation rate and trough $\mathrm{FEV}_{1}$ was assessed. Moderate exacerbations were events requiring treatment with antibiotics and/or oral/systemic corticosteroids. Severe exacerbations were events resulting in hospitalization or death. The incidence of on-treatment adverse events (AEs), serious AEs (SAEs), AEs of special interest (AESI), and mortality was also assessed. In this post hoc analysis, outcomes were evaluated in the subgroups of patients enrolled in North America (United States [including Puerto Rico], Canada) and Western Europe (pre-defined 
prior to unblinding as the European Economic Area and included Austria, Belgium, Czech Republic, Denmark, Finland, France, Germany, Netherlands, Norway, Poland, Romania, Spain, Sweden, United Kingdom). Details of sample size calculations for the intent-to-treat (ITT) population have been described previously. 8,12 The trial was not powered for subgroup analysis by region. The ITT population included all randomized patients, except those randomized in error. The North America and Western Europe subgroups were derived from the ITT population. Statistical analyses are described in the online supplement.

\section{Results}

\section{Patients}

Of 10,355 patients in the ITT population, 3164 (31\%) were enrolled in Western Europe (1252 to FF/UMEC/ VI, 1274 to FF/VI, 638 to UMEC/VI) and 2639 (25\%) in North America (1071 to FF/UMEC/VI, 1046 to FF/VI, 522 to UMEC/VI). Baseline characteristics for each region (all treatments combined), are shown in Table 1 and were similar between the 3 treatment groups within each population (Supplementary Table 1 in the online supplement).

There were some between-region differences in baseline characteristics, notably a lower proportion of males in North America (50\%) than in Western Europe (64\%) and the ITT population (66\%), a higher mean number of smoking pack years in North America (52.0) than in the ITT population (46.6) and Western Europe (43.2), a higher baseline SGRQ total score in North America (54.8) than in Western Europe (48.3) or the ITT population (50.2), and a lower proportion of patients experiencing $\geq 2$ moderate or $\geq 1$ severe exacerbation in the prior year in North America (66\%) than in Western Europe (71\%) and the ITT population (70\%). The proportion of patients on an inhaled corticosteroid (ICS)+long-acting beta2agonist (LABA)+long-acting muscarinic antagonist (LAMA) triple therapy at screening was higher in Western Europe (51\%) than in North America (46\%) or the ITT population (40\%), as was the proportion on $L A M A+L A B A$ at screening (19\% versus $4 \%$ and $9 \%$, respectively), while fewer patients were on ICS+LABA at screening in Western Europe (15\%) than in North America (31\%) or the ITT population (32\%). Most patients had blood eosinophil levels $\geq 100$ cells $/ \mu \mathrm{L}$ in all populations (Figure 1). A lower proportion of patients had blood eosinophil counts $<100$ cells $/ \mu \mathrm{L}$ or $<300$ cells/ $\mu \mathrm{L}$ in Western Europe (18\% and $76 \%$, respectively) than in North America (28\% and $82 \%$, respectively) or the ITT population (25\% and $78 \%$, respectively). Baseline blood eosinophil counts by country are given in Supplementary Table 2 (mean), and Supplementary Figure 1 and Supplementary Figure 2 (distribution) in the online supplement.

\section{On-treatment Moderate/Severe Exacerbations}

In Western Europe, moderate/severe exacerbation rates were highest in the United Kingdom, followed by France and Denmark, and lowest in Romania and Poland (Figure 2). In North America, rates were higher in Canada (Figure 2). FF/UMEC/VI significantly reduced moderate/severe exacerbation rate and risk (time-to-first) versus either dual therapy in both regions, consistent with ITT results (Figure 3 and Figure 4). Rate and risk reduction with FF/UMEC/ VI versus FF/VI were numerically greater in Western Europe than in North America or the ITT population, whereas for FF/UMEC/VI versus UMEC/VI, it was numerically greater in North America than in Western Europe or the ITT population (Figure 3 and 4). There was no significant interaction between treatment and region for this endpoint (Supplementary Table 3 in the online supplement).

\section{Trough Forced Expiratory Volume in 1 Second} Consistent with ITT results, FF/UMEC/VI significantly increased trough $\mathrm{FEV}_{1}$ at Week 52 versus FF/VI in both regions, with numerically greater between-treatment increases in Western Europe than in North America or the ITT population (Figure 5). FF/UMEC/VI significantly increased trough FEV 1 versus UMEC/VI in Western Europe and the ITT population. The point estimate favored FF/ UMEC/VI over UMEC/VI in North America but was not statistically significant (Figure 5). Improvement in trough $\mathrm{FEV}_{1}$ with $\mathrm{FF} / \mathrm{UMEC} / \mathrm{VI}$ versus $\mathrm{UMEC} / \mathrm{VI}$ was numerically greater in Western Europe than in North America, and similar between Western Europe and the ITT population (Figure 5). There was no significant interaction between treatment and region for this endpoint (Supplementary Table 3 in the online supplement). 


\section{Table 1. Baseline Characteristics: Intent-to-Treat Populations}

\begin{tabular}{|c|c|c|c|}
\hline & $\begin{array}{l}\text { Western Europe } \\
\qquad(\mathrm{N}=3164)\end{array}$ & $\begin{array}{c}\text { North America } \\
\qquad(\mathrm{N}=2639)\end{array}$ & $\begin{array}{c}\text { ITT } \\
(\mathrm{N}=10,355)\end{array}$ \\
\hline Age, mean (SD), years & $64.2(8.0)$ & $65.1(8.5)$ & $65.3(8.3)$ \\
\hline Male, $\mathrm{n}(\%)$ & $2014(64)$ & $1330(50)$ & $6870(66)$ \\
\hline \multicolumn{4}{|l|}{ Ethnicity, n (\%) } \\
\hline Not Hispanic/Latino & $3108(98)$ & $2564(97)$ & $8693(84)$ \\
\hline Hispanic/Latino & $55(2)$ & $75(3)$ & $1661(16)$ \\
\hline BMI, mean (SD), $\mathrm{kg} / \mathrm{m}^{2}$ & $27.1(5.7)$ & $28.4(6.8)$ & $26.6(6.1)$ \\
\hline \multicolumn{4}{|l|}{ Smoking Status, n (\%) } \\
\hline Former smoker & $1895(60)$ & $1611(61)$ & $6768(65)$ \\
\hline Current smoker & $1269(40)$ & $1028(39)$ & $3587(35)$ \\
\hline Smoking History (pack years), mean (SD) & $43.2(22.7)$ & $52.0(28.3)$ & $46.6(26.6)$ \\
\hline SGRQ Total Score, mean (SD) & $48.3(15.8)$ & $54.8(15.2)$ & $50.7(16.9)$ \\
\hline Post-bronchodilator FEV $\mathbf{1}, \mathrm{L}$, mean (SD) & $1.345(0.482)$ & $1.225(0.491)$ & $1.272(0.486)$ \\
\hline Post-bronchodilator FEV $\mathbf{1} \%$ Predicted, mean (SD) & $46.0(14.0)$ & $44.3(14.9)$ & $45.5(14.8)$ \\
\hline Post-bronchodilator FVC, L, mean (SD) & $2.805(0.835)$ & $2.589(0.832)$ & $2.726(0.819)$ \\
\hline Post-bronchodilator FEV 1 / FVC Ratio, mean (SD) & $0.484(0.115)$ & $0.476(0.118)$ & $0.470(0.120)$ \\
\hline \multicolumn{4}{|l|}{ Exacerbation History in Prior 12 Months, $\mathrm{n}(\%)$} \\
\hline 1 moderate and 0 severe & $932(29)$ & $887(34)$ & $3056(30)$ \\
\hline$\geq 2$ moderate or $\geq 1$ severe & $2232(71)$ & $1752(66)$ & $7299(70)$ \\
\hline Blood Eosinophil Count (cells $/ \mu \mathrm{L})$, median (IQR) & $180(110-280)$ & $150(90-250)$ & $170(90-270)$ \\
\hline \multicolumn{4}{|l|}{ COPD Medication at Screening, ${ }^{\mathrm{a}} \mathrm{n}(\%)$} \\
\hline ICS+LAMA+LABA & $1612(51)$ & $1217(46)$ & $4183(40)$ \\
\hline LAMA+LABA & $589(19)$ & $100(4)$ & $934(9)$ \\
\hline ICS+LABA & $467(15)$ & $818(31)$ & $3341(32)$ \\
\hline LAMA & $271(9)$ & $226(9)$ & $831(8)$ \\
\hline
\end{tabular}

${ }^{\mathrm{a} B e t w e e n}$ day of screening -3 days and date of screening (inclusive).

ITT=intent-to-treat; $\mathrm{SD}=$ standard deviation; BMI=body mass index; SGRQ=St George's Respiratory Questionnaire; FEV 1 =forced expiratory volume in 1 second; FVC=forced vital capacity; IQR=interquartile range; COPD=chronic obstructive pulmonary disease; ICS=inhaled corticosteroid; LAMA=long-acting muscarinic antagonist; LABA=long-acting beta2-agonist

\section{SGRQ Total Score}

All treatments improved SGRQ total score in both regions and in the ITT population, but statistically significant improvements were only demonstrated with FF/UMEC/VI versus FF/VI and UMEC/VI in Western Europe and the ITT population (Figure 6A). The magnitude of improvement from baseline in SGRQ total score with FF/UMEC/VI was greatest in the ITT population and smallest in Western Europe. Patients receiving either dual therapy regimen in Western Europe also experienced the smallest improvement in SGRQ total score compared with patients in North America and the ITT population. However, between-treatment differences for FF/UMEC/VI versus both dual therapies were numerically greater in Western Europe than in North
America or the ITT population (Figure 6A). There was evidence of an overall treatment difference for SGRQ total score between regions (overall $P=.054$ ), which was mainly driven by the comparison between FF/UMEC/VI and FF/VI ( $P=.018$ ) (Supplementary Table 3 in the online supplement).

The proportion of SGRQ responders at Week 52 was significantly higher with FF/UMEC/VI than FF/VI or UMEC/VI in Western Europe and the ITT population. In North America, statistically significant differences were seen with FF/UMEC/VI versus UMEC/VI $(P=.002)$ but not FF/VI $(P=.081)$ (Figure 6B).

\section{Safety}

In both regions, the overall $\mathrm{AE}$ profile of $\mathrm{FF} /$ $\mathrm{UMEC} / \mathrm{VI}$ was broadly similar to that of FF/VI and 


\section{Figure 1. Baseline Blood Eosinophil Counts: Intent-to-Treat Populations}

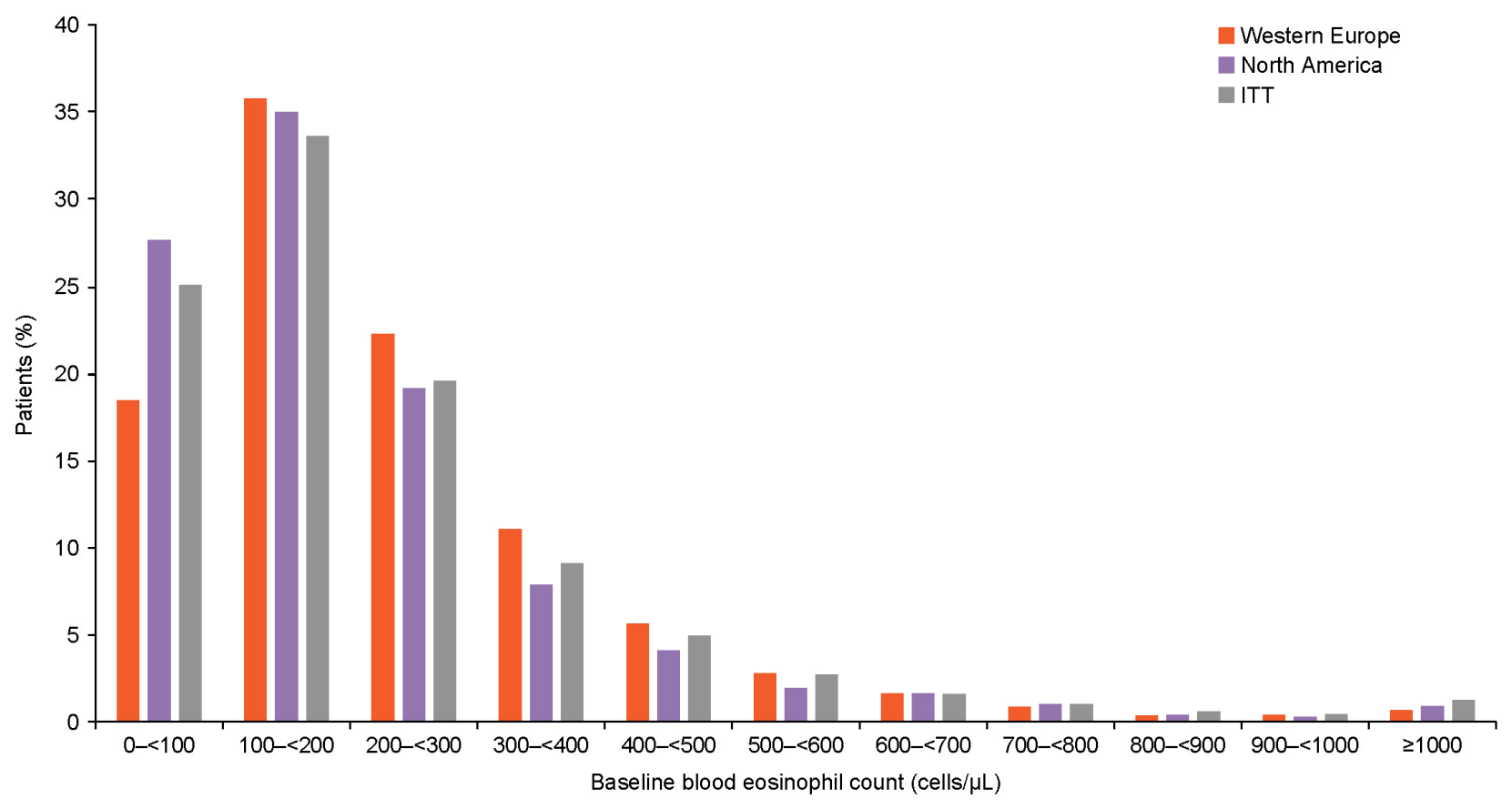

ITT=intent-to-treat

\section{Figure 2. Rate of On-treatment Moderate/Severe Exacerbations per Patient-Year by Country in Western Europe and North America ${ }^{a}$}

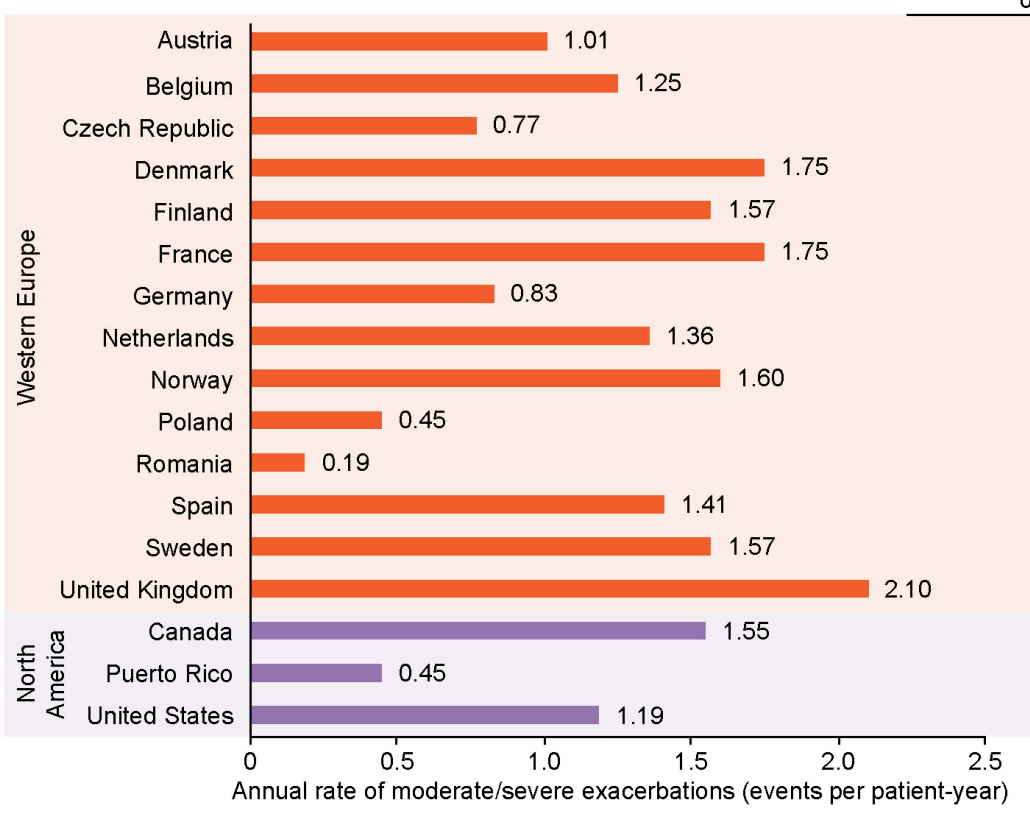

\begin{tabular}{ccc}
$\begin{array}{c}\text { Number } \\
\text { of patients }\end{array}$ & $\begin{array}{c}\text { Duration } \\
\text { at risk }\end{array}$ & $\begin{array}{c}\text { Patients with } \\
\text { moderate/severe } \\
\text { exacerbation, } \mathrm{n}(\%)\end{array}$ \\
\hline 119 & 102.9 & $59(50)$ \\
109 & 104.5 & $58(53)$ \\
143 & 134.0 & $60(42)$ \\
90 & 66.4 & $65(72)$ \\
76 & 63.2 & $48(63)$ \\
134 & 111.5 & $87(65)$ \\
1187 & 996.8 & $513(43)$ \\
301 & 238.2 & $197(65)$ \\
76 & 51.3 & $40(53)$ \\
88 & 80.8 & $29(33)$ \\
103 & 98.9 & $17(17)$ \\
499 & 443.3 & $316(63)$ \\
92 & 65.0 & $63(68)$ \\
147 & 113.0 & $110(75)$ \\
212 & 171.3 & $132(62)$ \\
21 & 15.5 & $4(19)$ \\
2406 & 1927.7 & $1298(54)$ \\
& &
\end{tabular}

aall treatments combined 


\section{Figure 3. Rate of On-treatment Moderate/Severe Exacerbations}

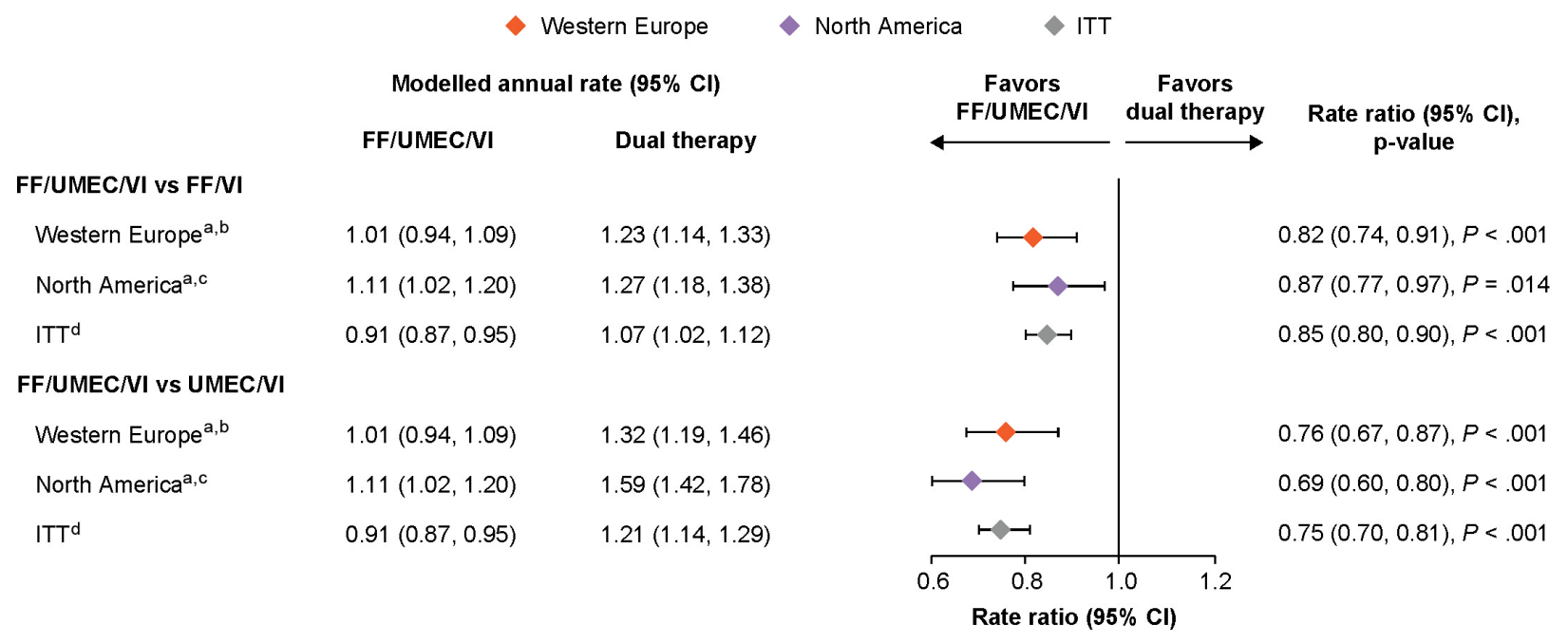

aPost hoc analysis

${ }^{\mathrm{b}} \mathrm{N}=3164$ (FF/UMEC/VI, $\mathrm{n}=1252 ; \mathrm{FF} / \mathrm{VI}, \mathrm{n}=1274 ; \mathrm{UMEC} / \mathrm{VI}, \mathrm{n}=638$ )

${ }^{\mathrm{C}} \mathrm{N}=2639$ (FF/UMEC/VI, $\left.\mathrm{n}=1071 ; \mathrm{FF} / \mathrm{VI}, \mathrm{n}=1046 ; \mathrm{UMEC} / \mathrm{VI}, \mathrm{n}=522\right)$

${ }^{\mathrm{d}} \mathrm{N}=10,355$ (FF/UMEC/VI, n=4151; FF/VI, n=4134; UMEC/VI, n=2070)

ITT=intent-to-treat; $\mathrm{FF}=$ fluticasone furoate; $\mathrm{UMEC}=$ umeclidinium; $\mathrm{VI}=$ vilanterol; $\mathrm{CI}=$ confidence interval

\section{Figure 4. Risk/Time-to-First of On-treatment Moderate/Severe Exacerbations}

\begin{tabular}{|c|c|c|c|c|c|}
\hline \multicolumn{6}{|c|}{ Western Europe } \\
\hline & \multicolumn{2}{|c|}{ Patients with an event, $n / N(\%)$} & \multirow{2}{*}{$\begin{array}{c}\text { Favors } \\
\text { FF/UMEC/NI }\end{array}$} & \multirow{2}{*}{$\begin{array}{c}\text { Favors } \\
\text { dual therapy }\end{array}$} & \multirow{2}{*}{$\begin{array}{l}\text { Hazard ratio }(95 \% \mathrm{Cl}) \\
\text { p-value }\end{array}$} \\
\hline & FF/UMEC/VI & Dual therapy & & & \\
\hline \multicolumn{6}{|c|}{ FF/UMEC/VI vs FF/VI } \\
\hline Western Europe ${ }^{a}$ & $632 / 1252(50)$ & $686 / 1274(54)$ & $\longmapsto \longrightarrow$ & & $0.81(0.73,0.90), P<.001$ \\
\hline North Americaa & $573 / 1071(54)$ & $561 / 1046(54)$ & $\longmapsto \bullet$ & & $0.87(0.77,0.98), P=.018$ \\
\hline ITT & $1959 / 4151(47)$ & $2039 / 4134(49)$ & $\vdash \diamond$ & & $0.85(0.80,0.91), P<.001$ \\
\hline \multicolumn{6}{|c|}{ FF/UMEC/VI vs UMEC/VI } \\
\hline Western Europe ${ }^{a}$ & $632 / 1252(50)$ & $344 / 638(54)$ & $\longmapsto \bullet$ & & $0.83(0.73,0.95), P=.005$ \\
\hline North America ${ }^{a}$ & $573 / 1071(54)$ & $300 / 522(57)$ & $\longmapsto$ & & $0.78(0.68,0.89), P<.001$ \\
\hline \multirow[t]{3}{*}{ ITT } & $1959 / 4151(47)$ & $1036 / 2070(50)$ & $\mapsto \bullet$ & & $0.84(0.78,0.91), P<.001$ \\
\hline & & & $\begin{array}{lll}0.6 & 0.8 & 1\end{array}$ & $\begin{array}{ll}1.0 & 1.2\end{array}$ & \\
\hline & & \multicolumn{4}{|c|}{ Hazard ratio $(95 \% \mathrm{Cl})$} \\
\hline
\end{tabular}

${ }^{\text {apost hoc analysis }}$

ITT=intent-to-treat; $\mathrm{FF}=$ fluticasone furoate; $\mathrm{UMEC}=$ umeclidinium; VI=vilanterol; $\mathrm{CI}=$ confidence interval

UMEC/VI. However, while pneumonia AESI incidence was higher in ICS-containing arms compared with UMEC/VI in North America and the ITT population, this was not seen in Western Europe where incidences were similar across all treatment arms (Table 2). Incidence of SAEs and fatal SAEs of pneumonia was low ( $\leq 5 \%$ and $<1 \%$, respectively), with no difference between treatment groups and across regions. 


\section{Figure 5. Change from Baseline in Trough Forced Expiratory Volume (ml) in 1 Second at Week 52}

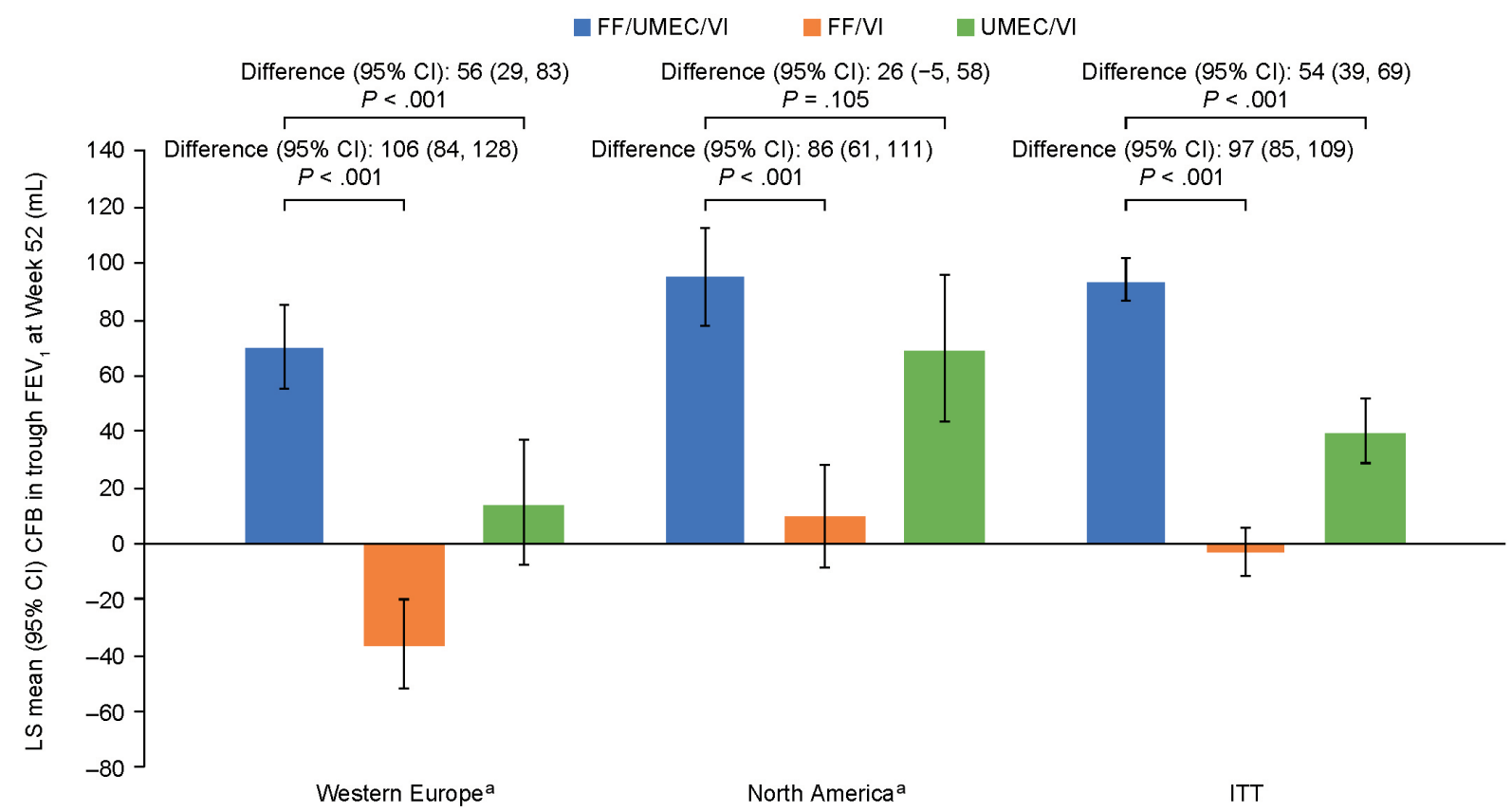

aPost hoc analysis

$\mathrm{FF}=$ fluticasone furoate; $\mathrm{UMEC}=$ umeclidinium; VI=vilanterol; ITT=intent-to-treat; $\mathrm{CI}=$ confidence interval; LS=least squares; $\mathrm{CFB}=$ change from baseline; $\mathrm{FEV}_{1}=$ forced expiratory volume in 1 second

\section{Discussion}

The IMPACT trial demonstrated the superiority of once-daily single-inhaler FF/UMEC/VI triple therapy over FF/VI or UMEC/VI dual therapy in reducing on-treatment moderate/severe exacerbation rates in a global population of patients with symptomatic COPD and a history of exacerbations. ${ }^{8}$ Results from this geographical analysis in Western Europe and North America were broadly consistent with the benefits shown in the overall ITT population, and reductions in moderate/severe exacerbation rate and risk and improvements in lung function and health status were seen with FF/UMEC/VI compared with FF/VI or UMEC/VI. The safety profile of all treatments in both regions was generally in line with that in the ITT population. As expected, based on the class effect for ICS, ${ }^{13}$ the incidence of pneumonia was higher in ICS-containing arms compared with UMEC/VI in North America and the ITT population; interestingly this was not seen in Western Europe.

Studies have highlighted the burden of COPD in Western Europe and North America, revealing considerable variation across countries in patient characteristics, patterns of disease severity, symptoms, medication availability, access, and health care utilization. ${ }^{10,14,15}$ These differences could impact the efficacy of COPD therapies in different populations. In this analysis, improvements in the rate and risk of moderate/severe exacerbations, trough $\mathrm{FEV}_{1}$ and SGRQ responders with FF/UMEC/VI compared with UMEC/VI and FF/VI in both regions were generally of a similar magnitude to those in the ITT population. FF/UMEC/VI significantly increased trough $\mathrm{FEV}_{1}$ at Week 52 versus FF/VI in both regions; while a numerically greater between-treatment increase was seen in Western Europe compared with in North America and the ITT population, this likely reflects the worsening of lung function in the FF/VI group in Western Europe rather than an increase in efficacy with FF/UMEC/VI. Statistically significant improvements in the SGRQ total score were demonstrated with FF/UMEC/VI versus FF/ VI and UMEC/VI in Western Europe and the ITT population but not in North America. The interaction term indicated an overall treatment difference 


\section{Figure 6. (A) Change from Baseline in St George's Respiratory Questionnaire Total Score and (B) St George's Respiratory Questionnaire Responders at Week 52}
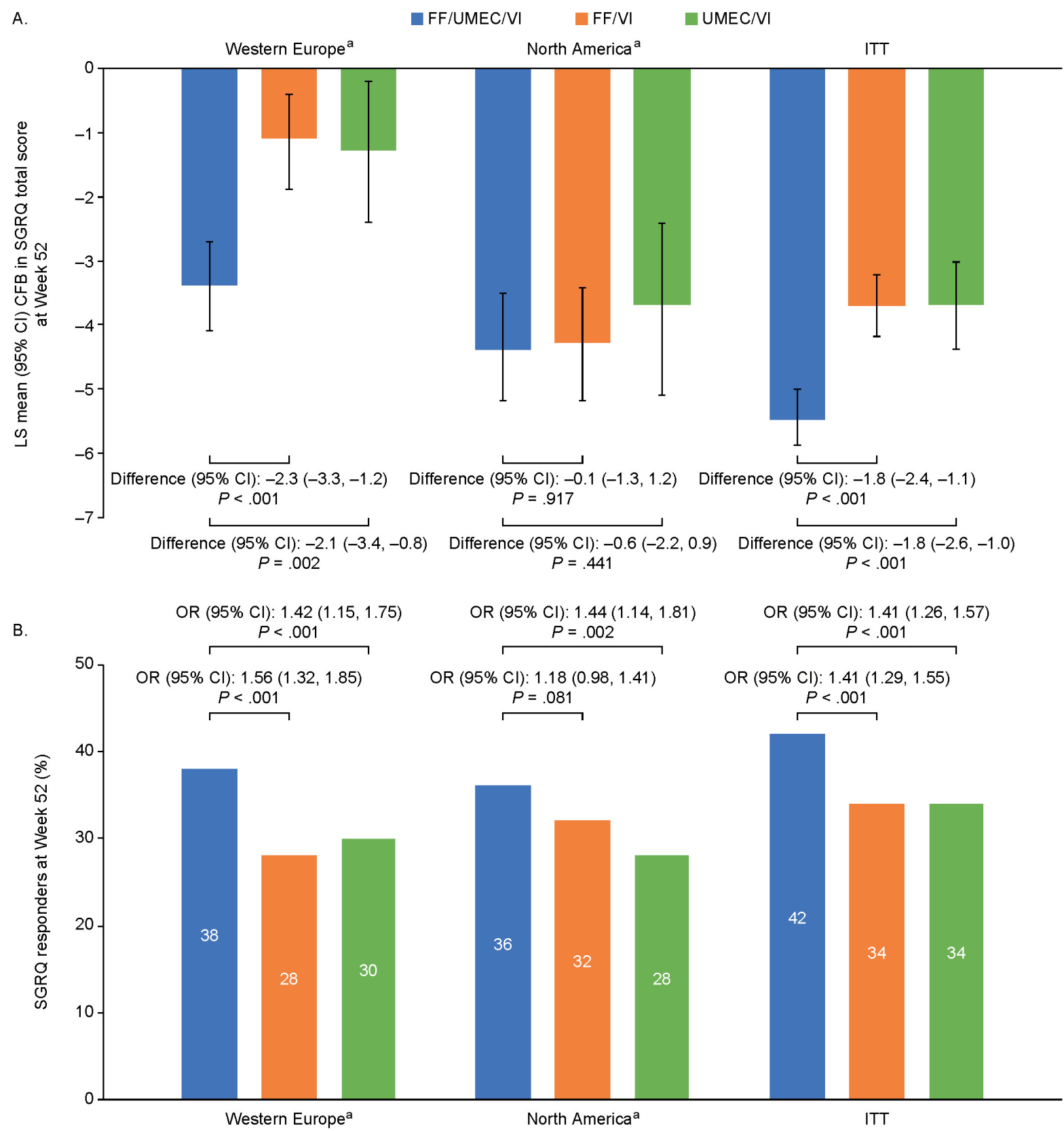

aPost hoc analysis

SGRQ responders are patients with a $\geq 4$-unit decrease from baseline in SGRQ total score.

$\mathrm{FF}=$ fluticasone furoate; UMEC=umeclidinium; VI=vilanterol; ITT=intent-to-treat; LS=least squares; $\mathrm{CFB}=\mathrm{change}$ from baseline; $\mathrm{SGRQ}=\mathrm{St}$ George's Respiratory Questionnaire; $\mathrm{CI}=$ confidence interval; OR=odds ratio 


\section{Table 2. Incidence of On-Treatment Adverse Effects: Intent-to-Treat Populations}

\begin{tabular}{|c|c|c|c|c|c|c|c|c|c|}
\hline \multirow[b]{2}{*}{ AE Incidence, n (\%) } & \multicolumn{3}{|c|}{ Western Europe } & \multicolumn{3}{|c|}{ North America } & \multirow[b]{2}{*}{$\begin{array}{l}\text { FF/ } \\
\text { UMEC/ } \\
\text { VI } \\
n=4151\end{array}$} & \multirow{2}{*}{$\begin{array}{c}\text { ITT } \\
\text { FFNI } \\
n=4134\end{array}$} & \multirow[b]{2}{*}{$\begin{array}{l}\text { UMEC/ } \\
\mathrm{VI} \\
\mathrm{n}=2070\end{array}$} \\
\hline & $\begin{array}{c}\mathrm{FF} / \\
\text { UMEC/ } \\
\mathrm{V} / \\
\mathrm{n}=1252\end{array}$ & $\begin{array}{l}\mathrm{FF} N \mathrm{I} \\
\mathrm{n}=1274\end{array}$ & $\begin{array}{l}\text { UMECl } \\
\mathrm{VI} \\
\mathrm{n}=638\end{array}$ & $\begin{array}{c}\mathrm{FF} / \\
\text { UMEC/ } \\
\mathrm{V} / \\
\mathrm{n}=1071\end{array}$ & $\begin{array}{l}\mathrm{FFNI} \\
\mathrm{n}=1046\end{array}$ & $\begin{array}{c}\text { UMECl } \\
\mathrm{VI} \\
\mathrm{n}=522\end{array}$ & & & \\
\hline Any On-treatment AE & $880(70)$ & 845 (66) & $436(68)$ & $790(74)$ & $739(71)$ & $360(69)$ & $2897(70)$ & $2800(68)$ & 1429 (69) \\
\hline $\begin{array}{l}\text { Leading to permanent } \\
\text { study treatment } \\
\text { discontinuation/study } \\
\text { withdrawal }\end{array}$ & $87(7)$ & $114(9)$ & $58(9)$ & $75(7)$ & $98(9)$ & $57(11)$ & $252(6)$ & $327(8)$ & $187(9)$ \\
\hline
\end{tabular}

\section{On-treatment AESI}

\begin{tabular}{l|r|r|r|r|r|r|r|r|r}
\hline Anticholinergic Syndrome (SMQ) & $49(4)$ & $43(3)$ & $28(4)$ & $67(6)$ & $43(4)$ & $15(3)$ & $184(4)$ & $140(3)$ & $70(3)$ \\
\hline Asthma/Bronchospasm (SMQ) & $6(<1)$ & $2(<1)$ & $1(<1)$ & $15(1)$ & $19(2)$ & $6(1)$ & $27(<1)$ & $34(<1)$ & $16(<1)$ \\
\hline Cardiovascular Effects & $125(10)$ & $116(9)$ & $63(10)$ & $147(14)$ & $135(13)$ & $59(11)$ & $450(11)$ & $430(10)$ & $224(11)$ \\
\hline $\begin{array}{l}\text { Decreased BMD and Associated } \\
\text { Fractures }\end{array}$ & $24(2)$ & $25(2)$ & $14(2)$ & $41(4)$ & $25(2)$ & $13(2)$ & $98(2)$ & $85(2)$ & $37(2)$ \\
\hline Effects on Potassium & $4(<1)$ & $2(<1)$ & $3(<1)$ & $19(2)$ & $12(1)$ & $3(<1)$ & $34(<1)$ & $25(<1)$ & $8(<1)$ \\
\hline $\begin{array}{l}\text { Gastrointestinal Obstruction } \\
\text { (SMQ) }\end{array}$ & $2(<1)$ & $3(<1)$ & $0(0)$ & $5(<1)$ & $4(<1)$ & $0(0)$ & $9(<1)$ & $10(<1)$ & $2(<1)$ \\
\hline $\begin{array}{l}\text { Hyperglycemia/New Onset DM } \\
\text { (SMQ) }\end{array}$ & $43(3)$ & $29(2)$ & $29(5)$ & $50(5)$ & $48(5)$ & $24(5)$ & $152(4)$ & $117(3)$ & $73(4)$ \\
\hline Hypersensitivity & $54(4)$ & $45(4)$ & $26(4)$ & $66(6)$ & $57(5)$ & $31(6)$ & $196(5)$ & $195(5)$ & $95(5)$ \\
\hline LRTI Excluding Pneumonia & $39(3)$ & $42(3)$ & $13(2)$ & $42(4)$ & $36(3)$ & $29(6)$ & $200(5)$ & $199(5)$ & $108(5)$ \\
\hline Local Steroid Effects & $109(9)$ & $100(8)$ & $35(5)$ & $119(11)$ & $93(9)$ & $36(7)$ & $337(8)$ & $301(7)$ & $108(5)$ \\
\hline Ocular Effects & $21(2)$ & $16(1)$ & $6(<1)$ & $19(2)$ & $10(<1)$ & $5(<1)$ & $55(1)$ & $45(1)$ & $26(1)$ \\
\hline Pneumonia & $70(6)$ & $54(4)$ & $30(5)$ & $99(9)$ & $86(8)$ & $20(4)$ & $317(8)$ & $292(7)$ & $97(5)$ \\
\hline Tremor & $6(<1)$ & $2(<1)$ & $2(<1)$ & $1(<1)$ & $0(0)$ & $2(<1)$ & $8(<1)$ & $4(<1)$ & $6(<1)$ \\
\hline Urinary Retention & $0(0)$ & $3(<1)$ & $4(<1)$ & $6(<1)$ & $7(<1)$ & $2(<1)$ & $8(<1)$ & $12(<1)$ & $9(<1)$ \\
\hline Any On-treatment SAE & $272(22)$ & $262(21)$ & $149(23)$ & $264(25)$ & $228(22)$ & $124(24)$ & $895(22)$ & $850(21)$ & $470(23)$ \\
\hline Any On-treatment Fatal SAE & $19(2)$ & $17(1)$ & $11(2)$ & $18(2)$ & $15(1)$ & $13(2)$ & $68(2)$ & $76(2)$ & $49(2)$ \\
\hline
\end{tabular}

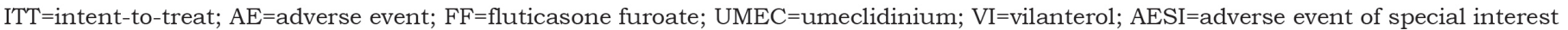
(AEs which have specified areas of interest for FF, UMEC, or VI, or for patients with COPD); SMQ=Standardized Medical Dictionary for Regulatory Activities Query; BMD=bone mineral density; DM=diabetes mellitus; LRTI=lower respiratory tract infection;

$\mathrm{SAE}=$ serious adverse event

between regions for this endpoint, mainly driven by the comparison between FF/UMEC/VI and FF/VI. Reasons for this are unknown but it is worth noting that the baseline SGRQ total score was higher in the North American region compared with the Western Europe and ITT populations, indicating worse health status and greater changes from baseline were seen in all treatment groups in North America compared with Western Europe. The proportion of SGRQ responders at Week 52 was consistent across all regions for each treatment group; however, the difference between FF/UMEC/VI and FF/VI in North America was not statistically significant.

Baseline characteristics were similar across the 2 regions and the ITT population, with a few exceptions. The median blood eosinophil count in North America was lower than in Western Europe and the ITT population, and the mean number of smoking pack years was higher. However, the percentage of patients with blood eosinophil counts $<100$ cell/ $\mu \mathrm{L}$ was lower in Western Europe than in North America. Given the association between cigarette smoking and reduced ICS sensitivity, ${ }^{16}$ along with improved ICS sensitivity in patients with higher eosinophil levels, ${ }^{17}$ patients 
in North America may have been expected to have slightly lower sensitivity to ICS-containing therapies based on their baseline characteristics. However, this was not reflected in the treatment effect of FF/UMEC/ $\mathrm{VI}$ versus UMEC/VI and FF/VI on moderate/severe exacerbations. Differences in baseline treatment were noted according to region prior to randomization. The proportion of patients on LAMA+LABA therapy at screening was higher in Western Europe (19\%) than in North America (4\%), while the proportion on ICS+LABA or ICS+LAMA+LABA at screening was higher in North America (77\%) than in Western Europe (66\%). This may indicate different therapeutic requirements for patients enrolled in North America, which may explain why patients in this region appeared more responsive to FF than patients in Western Europe. Nevertheless, these differences in baseline treatment across regions did not appear to affect the treatment effect of FF/UMEC/VI versus either dual therapy.

There were large between-country variations in moderate/severe exacerbation rates, from 0.19 per patient-year in Romania to 2.10 per patient-year in the United Kingdom. These may be due to differences in patient demographics and clinical characteristics between countries and highlight the potential difficulties in performing cross-trial comparisons unless correction for baseline demographics can be performed. When interpreting these between-country differences, it is worth noting that while the individual patient time at risk was broadly similar between countries, there was a large range of total duration at risk across countries, reflecting the varying sample sizes. As greater duration at risk would give more precision to the point estimates for annual rates of moderate/severe exacerbation, results in countries of small sample size need to be interpreted with caution.

Other studies have evaluated single-inhaler triple therapy versus dual or monotherapies; ${ }^{18-21}$ however, regional analyses have not been reported. The large sample size and global scope of the IMPACT trial allows for a robust comparison across different regions and the ITT population. Differences in national and international guidelines for COPD exist, including differences in treatment recommendations, potentially leading to regional differences in patient care. ${ }^{1,22}$ It is important to understand these similarities and differences and how they may potentially affect patient management and inform future guideline development both globally and nationally. While the distribution and prevalence of COPD in different geographic regions has been wellstudied, ${ }^{23,24}$ a large-scale comparative assessment of how treatment efficacy can vary by region has not been previously described. Results in these 2 IMPACT regional subpopulations were consistent with the overall study population and demonstrate the favorable benefit-risk profile of single-inhaler FF/UMEC/VI triple therapy over FF/VI or UMEC/ VI dual therapy in patients with symptomatic COPD and a history of exacerbations. However, it should be noted that these analyses are descriptive and were conducted post hoc, and the study was not powered to demonstrate statistical significance for any endpoints by or between regions.

\section{Conclusions}

In this regional analysis of the IMPACT trial, FF/ UMEC/VI significantly reduced the rate and risk of moderate/severe exacerbations versus FF/VI and UMEC/VI in both the Western Europe and North America regions. Treatment responses were similar with respect to exacerbations and lung function for both regions and the ITT population. However, there were some differences in SGRQ total score between regions, with no differential effect observed between FF/UMEC/VI and dual therapies in North America, unlike in Western Europe and the ITT population. Safety profiles with FF/UMEC/VI, UMEC/VI and $\mathrm{FF} / \mathrm{VI}$ were similar in both regions and the ITT population although the ICS class effect of increased pneumonia incidence was seen in North America and the ITT population, but not in Western Europe. These efficacy and safety results in patients with symptomatic COPD and a history of exacerbations continue to support a positive benefit-risk profile with FF/UMEC/VI.

\section{Acknowledgements}

Author contributions: The authors meet criteria for authorship as recommended by the International Committee of Medical Journal Editors, take responsibility for the integrity of the work as a whole, contributed to the writing and reviewing of the manuscript, and have given final approval for the version to be published. All authors had full access to the data in this study and take complete responsibility 
for the integrity of the data and accuracy of the data analysis. A Bourdin, G Criner, G Devouassoux, M.Dransfield, DMG Halpin, JM Echave-Sustaeta María-Tomé, NA Hanania, R Kalhan, and TM Siler contributed to the acquisition of data and data analysis and interpretation. MK Han, CE Jones, P Lange, S Lettis, DA Lomas, N Martin, FJ Martinez, H Quasny, L Sail, D Singh, B Thomashow, H Watz and R Wise contributed to data analysis and interpretation. DA Lipson contributed to study conception and design, and data analysis and interpretation.

Dataavailability: Anonymizedindividual participant data and study documents can be requested for further research from www.clinicalstudydatarequest. com.

\section{Declaration of Interests}

Editorial support (in the form of writing assistance, assembling figures, collating author comments, grammatical editing and referencing) was provided by Chrystelle Rasamison, Fishawack Indicia Ltd, United Kingdom, and was funded by GSK.

A Bourdin was an investigator in the IMPACT trial and has received personal fees and a grant from Boehringer Ingelheim, personal fees from AstraZeneca, Chiesi, GSK, Novartis and SanofiRegeneron, and is an investigator in clinical trials from Nuvaira, Pulmonx, Actelion, MSD, United Therapeutic, Vertex, Acceleron, and Galapagos. G Criner has received personal fees from Almirall, AstraZeneca, Boehringer Ingelheim, Chiesi, CSA Medical, Eolo, GSK, HGE Technologies, Novartis, Nuvaira, Olympus, Pulmonx, and Verona. G Devouassoux has received personal fees from AstraZeneca, Novartis Pharma, GSK, Chiesi, and Boehringer Ingelheim, and contracted clinical trial support from AstraZeneca, GSK, Novartis Pharma, ALK, Chiesi, and Boehringer Ingelheim. M Dransfield has received personal fees from Boehringer Ingelheim, PneumRx/BTG, Genentech, Quark Pharmaceuticals, Mereo, AstraZeneca and GSK, a grant from the Department of Defense, and contracted clinical trial support from PneumRx/BTG, Novartis, AstraZeneca, Yungjin, Pulmonx, Boston Scientific, Boehringer Ingelheim, and GSK. DMG Halpin reports personal fees from AstraZeneca, Boehringer Ingelheim, Chiesi, GSK, Novartis, and Pfizer, and non-financial support Boehringer Ingelheim and Novartis. MK Han has received personal fees from AstraZeneca, Boehringer Ingelheim, Merck, Mylan and GSK and research support from Novartis and Sunovion. CE Jones, S Lettis, DA Lipson, N Martin, H Quasny, and L Sail are GSK employees and hold stock/shares in GSK. R Kalhan reports grants from the National Heart, Lung, and Blood Institute during the conduct of the study, grants and personal fees from Boehringer Ingelheim, grants from PneumRx (BTG), grants from Spiration, grants and personal fees from AstraZeneca, personal fees from CVS Caremark, personal fees from Aptus Health, grants and personal fees from GSK, personal fees from Boston Scientific, and personal fees from Boston Consulting Group. P Lange reports personal fees from GSK, AstraZeneca, Chiesi and Boehringer Ingelheim, and grant support from Boehringer Ingelheim.

DA Lomas reports personal fees from GSK and Grifols; he chaired the GSK Respiratory Therapy Area Board in 2012-2015. JM Echave-Sustaeta MaríaTomé has received personal fees from GSK and was an investigator in the IMPACT trial. FJ Martinez has received personal fees and non-financial support from, AstraZeneca, Boehringer Ingelheim, Genentech, GSK, Inova Fairfax Health System, Miller Communications, National Society for Continuing Education, Novartis, Pearl Pharmaceuticals, PeerView Communications, Prime Communications, Puerto Rico Respiratory Society, Chiesi, Sunovion, Theravance, Potomac, University of Alabama-Birmingham, Physicians Education Resource, Canadian Respiratory Network, Teva and Dartmouth; and personal fees from Columbia University, MD Magazine, Methodist Hospital Brooklyn, New York University, UpToDate, WebMD/MedScape, Patara/Respivant, the American Thoracic Society, Rockpointe, Rare Disease Healthcare Communications and the France Foundation, and has taken part in advisory boards for AstraZeneca, Boehringer Ingelheim, ProterrixBio, Genentech, Novartis, Pearl Pharmaceuticals, Theravance, Zambon, Gala, Chiesi, GSK, Sunovion, and Teva, steering committees for AstraZeneca, Pearl Pharmaceuticals, Afferent/Merck, Gilead, Nitto, Patara/Respivant, Biogen, Veracyte, Prometic, Bayer, ProMedior and GSK, and been an advisor for Bridge Biotherapeutics. TM Siler has received research grants from AstraZeneca, Boehringer Ingelheim, Chiesi Farmaceutici, Compleware, Evidera (PPD), Forest Research Institute (now AstraZeneca), GSK, 
Novartis, Pearl Therapeutics, Proterix BioPharma, Oncocyte, Sanofi, Seer, Sunovion, Teva, Theravance BioPharma, Vapotherm, Restorbio and Westward, and personal fees from GSK, Sunovion, Theravance Biopharma and Vapotherm. D Singh reports personal fees from GSK, AstraZeneca, Boehringer Ingelheim, Chiesi, Cipla, Genentech, Glenmark, Menarini, Mundipharma, Novartis, Peptinnovate, Pfizer, Pulmatrix, Theravance, and Verona, and grant support from AstraZeneca, Boehringer Ingelheim, Chiesi, Glenmark, Menarini, Mundipharma, Novartis, Pfizer, Pulmatrix, Theravance and Verona. B Thomashow has taken part in advisory boards for AstraZeneca and GSK. H Watz reports personal fees from AstraZeneca, Boehringer Ingelheim, BerlinChemie, Chiesi, GSK, Novartis, Takeda, and Verona Pharma. R Wise reports personal fees from AstraZeneca/Medimmune/ Pearl, Boehringer Ingelheim, Contrafect, Pulmonx, Roche, Spiration, Sunovion, Circassia, Pneuma, Verona, Mylan/Theravance, Propeller Health, AbbVie GSK, Merck, Kiniksa and Galderma, and has received research grants from AstraZeneca/ MedImmune/Pearl, Boehringer Ingelheim, Pearl Therapeutics, Sanofi-Aventis and GSK. NA Hanania was an investigator on the IMPACT trial and reports receiving personal fees from GSK, AstraZeneca, Boehringer Ingelheim, Sanofi Genzyme, Novartis, Regeneron, Genentech, Sunovion, and Mylan. He also received research support from GSK, Boehringer Ingelheim, Sanofi Genzyme, Novartis and Astra Zeneca. ELLIPTA is owned by or licensed to the GSK Group of Companies. 


\section{References}

1. Global Initiative for Chronic Obstructive Lung Disease (GOLD). Global strategy for the diagnosis, management, and prevention of COPD, 2019 report. GOLD website. Published 2018. Accessed August 2020. https://www.goldcopd.org.

2. World Health Organization (WHO). Projections of mortality and causes of death, 2016 to 2060. WHO website. Published 2016. Accessed August 2020. https://www.who.int/healthinfo/global_burden_ disease/projections/en/

3. Halbert RJ, Natoli JL, Gano A, Badamgarav E, Buist AS, Mannino DM. Global burden of COPD: systematic review and meta-analysis. Eur Respir J. 2006;28(3):523-532. doi: https://doi.org/10.1183/09031936.06.00124605

4. World Health Organization (WHO). Causes of COPD. WHO website. Updated 2020. Accessed August 2020. https://www.who.int/ respiratory/copd/causes/en/

5. Fletcher MJ, Upton J, Taylor-Fishwick J, et al. COPD uncovered: an international survey on the impact of chronic obstructive pulmonary disease [COPD] on a working age population. BMC Public Health. 2011;11:612. doi: https://doi.org/10.1186/1471-2458-11-612

6. Kessler R, Partridge MR, Miravitlles M, et al. Symptom variability in patients with severe COPD: a pan-European cross-sectional study. Eur Respir J. 2011;37(2):264-272. doi: https://doi.org/10.1183/09031936.00051110

7. Landis SH, Muellerova H, Mannino DM, et al. Continuing to Confront COPD International Patient Survey: methods, COPD prevalence, and disease burden in 2012-2013. Int J Chron Obstruct Pulmon Dis. 2014;9:597-611. doi: https://doi.org/10.2147/COPD.S61854

8. Lipson DA, Barnhart F, Brealey N, et al. Once-daily single-inhaler triple versus dual therapy in patients with COPD. $N$ Engl $J$ Med. 2018;378(18):1671-1680.

doi: https://doi.org/10.1056/NEJMoa1713901

9. Adeloye D, Chua S, Lee C, et al. Global and regional estimates of COPD prevalence: systematic review and meta-analysis. $J$ Glob Health. 2015;5(2):020415. doi: https://doi.org/10.7189/jogh.05.020415

10. Ding B, DiBonaventura M, Karlsson N, Bergstrom G, Holmgren U. A cross-sectional assessment of the burden of COPD symptoms in the US and Europe using the National Health and Wellness Survey. Int $J$ Chron Obstruct Pulmon Dis. 2017;12:529-539.

doi: https://doi.org/10.2147/COPD.S114085

11. Global Initiative for Chronic Obstructive Lung Disease (GOLD). Global strategy for the diagnosis, management, and prevention of COPD, 2014 report. GOLD website. Published December 2013. Accessed August 2020. https://www.goldcopd.org.

12. Pascoe SJ, Lipson DA, Locantore N, et al. A phase III randomised controlled trial of single-dose triple therapy in COPD: the IMPACT protocol. Eur Respir J. 2016;48(2):320-330.

doi: https://doi.org/10.1183/13993003.02165-2015
13. Kew KM, Seniukovich A. Inhaled steroids and risk of pneumonia for chronic obstructive pulmonary disease. Cochrane Database Syst Rev. 2014(3):CD010115. doi: https://doi.org/10.1002/14651858.CD010115.pub2

14. Gruenberger JB, Vietri J, Keininger DL, Mahler DA. Greater dyspnea is associated with lower health-related quality of life among European patients with COPD. Int J Chron Obstruct Pulmon Dis. 2017;12:937944. doi: https://doi.org/10.2147/COPD.S123744

15. Wallace AE, Kaila S, Bayer V, et al. Health care resource utilization and exacerbation rates in patients with COPD stratified by disease severity in a commercially insured population. J Manag Care Spec Pharm. 2019;25(2):205-517.

doi: https://doi.org/10.18553/jmcp.2019.25.2.205

16. Tamimi A, Serdarevic D, Hanania NA. The effects of cigarette smoke on airway inflammation in asthma and COPD: therapeutic implications. Respir Med. 2012;106(3):319-328.

doi: https://doi.org/10.1016/j.rmed.2011.11.003

17. Bafadhel M, Peterson S, De Blas MA, et al. Predictors of exacerbation risk and response to budesonide in patients with chronic obstructive pulmonary disease: a post-hoc analysis of three randomised trials. Lancet Respir Med. 2018;6(2):117-126. doi: https://doi.org/10.1016/S2213-2600(18)30006-7

18. Ferguson GT, Rabe KF, Martinez FJ, et al. Triple therapy with budesonide/glycopyrrolate/formoterol fumarate with co-suspension delivery technology versus dual therapies in chronic obstructive pulmonary disease (KRONOS): a double-blind, parallel group, multicentre, phase 3 randomised controlled trial. Lancet Respir Med. 2018;6(10):747-758.

doi: https://doi.org/10.1016/S2213-2600(18)30327-8

19. Papi A, Vestbo J, Fabbri L, et al. Extrafine inhaled triple therapy versus dual bronchodilator therapy in chronic obstructive pulmonary disease (TRIBUTE): a double-blind, parallel group, randomised controlled trial. Lancet. 2018;391(10125):1076-1084. doi: https://doi.org/10.1016/S0140-6736(18)30206-X

20. Vestbo J, Papi A, Corradi M, et al. Single inhaler extrafine triple therapy versus long-acting muscarinic antagonist therapy for chronic obstructive pulmonary disease (TRINITY): a double blind, parallel group, randomised controlled trial. Lancet (London, England). 2017;389(10082):1919-1929.

doi: https://doi.org/10.1016/S0140-6736(17)30188-5

21. Lipson DA, Barnacle H, Birk R, et al. FULFIL Trial: Once-daily triple therapy for patients with chronic obstructive pulmonary disease. Am J Respir Crit Care Med. 2017;196(4):438-446. doi: https://doi.org/10.1164/rccm.201703-04490C

22. Miravitlles M, Vogelmeier C, Roche N, et al. A review of national guidelines for management of COPD in Europe. Eur Respir $\mathrm{J}$. 2016;47(2):625-637.

doi: https://doi.org/10.1183/13993003.01170-2015 
23. Blanco I, Diego I, Bueno P, et al. Geographical distribution of COPD prevalence in Europe, estimated by an inverse distance weighting interpolation technique. Int J Chron Obstruct Pulmon Dis. 2018;13:5767. doi: https://doi.org/10.2147/COPD.S150853

24. Doney B, Hnizdo E, Syamlal G, et al. Prevalence of chronic obstructive pulmonary disease among US working adults aged 40 to 70 years. National Health Interview Survey data 2004 to 2011. J Occup Environ Med. 2014;56(10):1088-1093.

doi: https://doi.org/10.1097/JOM.0000000000000232 